\title{
An innovative approach to the elimination of combustion foci at MSW landfills (on the example of the Rostov region).
}

\author{
Oleg Denisov ${ }^{1, *}$ and Elena Andreeva \\ ${ }^{1}$ Don State Technical University, Gagarin sq., 1, 344003 Rostov-on-Don, Russia
}

\begin{abstract}
The article is devoted to the search for an innovative approach to the elimination of combustion foci at solid municipal waste landfills. In connection with the increase in the number of solid municipal waste landfills near settlements, a number of geoecological problems are increasing. One of the most complex geoecological problems arising in connection with the operation of solid municipal waste landfills is the problem of the genesis and development of surface fires in the layer of household waste. At the same time, concern is caused not only by the actual dangerous factors of the spread of fire, but also by the subsequent significant pollution of the surface layer with air by combustion products, including those of a carcinogenic or mutagenic nature. To achieve this goal, the article describes an innovative approach to eliminating combustion foci at solid municipal waste landfills: an innovative device developed by the authors of the study - a mechanical fire hydrant for wetting burning deep layers of consumption waste with a fire-extinguishing liquid.
\end{abstract}

\section{Introduction}

In connection with the increase in the number of landfills for solid municipal (household) waste (solid municipal waste) near settlements, a number of geoecological problems associated with them are increasing and aggravating. This process has recently manifested itself not only in the world, the Russian Federation as a whole, but also within its individual administrative subjects, in particular, in the Rostov region $[1,2]$.

One of the most complex geoecological problems arising in connection with the operation of solid municipal waste landfills (solid municipal waste) is the problem of the genesis and development of surface fires in the layer of household waste. As shown in a number of scientific studies [3,4], ignition in the specified waste layer is caused by the formation of biogas, which contains, among other gases, methane, which is characterized by the ability to ignite spontaneously.

At the same time, concern is caused not only by the actual dangerous factors of the spread of fire, but also by the subsequent significant pollution of the surface layer with air by combustion products, including those of a carcinogenic or mutagenic nature. The proximity of settlements with populations of different age groups, as well as a number of geographic

\footnotetext{
* Corresponding author: ovd63@mail.ru
} 
factors affecting the diffusion of gaseous combustion products and technogenic aerosols, will undoubtedly determine the increased socio-ecological risks $[5,6]$.

Hence, the relevance of this study, as it seems to its authors, is associated with the growing need to ensure the environmental safety of solid municipal waste (solid municipal waste) landfills, within the surface layers of which, in connection with the intake of the organic component of municipal solid waste (solid municipal waste), which are part of solid municipal waste, often biogas is formed containing explosive components, including methane, as a result of which man-made fires develop, the area of which varies from several hundred to thousands of square meters.

Special attention is required in this case for solid municipal waste landfills located within the city limits, as, for example, in Rostov-on-Don [7,8] with a population of over 1 million people $(1,137,904$ people in 2020), as well as other settlements. At the same time, improving the environmental safety of such technogenic objects - solid municipal waste landfills implies the mandatory use of improved special equipment and devices that provide protection against technogenic fires, complicated by both the presence of fire hazardous objects on the ground and the proximity of settlements.

The object of this study is solid municipal waste landfills located in the Rostov region. Within which, according to the regional waste cadastre $[9,10]$, as of January 1, 2020, there were 257 waste disposal sites subject to reclamation. Basically, these places are represented by solid municipal waste dumps, which were created in the period of the $60-80 \mathrm{~s}$. XX century. In addition, according to information provided by individual entrepreneurs and a number of legal entities, as of January 1, 2020, there are 42 facilities for the disposal of solid municipal waste waste, 48 facilities for treatment, disposal, and neutralization of waste in the Rostov region.

Actually, solid municipal waste landfills (including solid waste landfills) on the territory of the Rostov region are represented in almost all its districts: in the village of Vesely, with. Samarskoe, Kovalevka village, Belaya Kalitva, x. Sheshaulov, Donetsk, Novoshakhtinsk, Volgodonsk (there are two solid waste landfills), Rybasovo, Orlovsky, Chertkovo, st. Kagalnitskaya, st. Bagaevskaya, Rostov-on-Don (3 solid waste landfills), x. Mikhailovka, Novocherkassk, Kamensk - Shakhtinsky, Shakhty, x. Nikolaevsky, Gukovo, Semikarakorsk (2 solid waste landfills), p. Kagalnik, Morozovsk, Zernovaya settlement, with. Zavetinskoe, s. Dubovskoe, sl. B. Martynovka, Popovka, Zimovniki.

However, from January 1, 2019, from this number of landfills, only those that are included in the State Register of Waste Disposal Facilities are accepted; on the territory of the Rostov region there are 24 such MSW landfills included in the State Register of Waste Disposal Facilities.

It is important to note that during the transition to a new system of solid municipal waste management on the basis of the Federal Law of 24.06.1998 №89 "On production and consumption waste" 8 regional operators - Intermunicipal ecological waste processing complexes for the management of solid municipal waste in the Rostov region were identified: Myasnikovsky, Salsky, Morozovsky, Volgodonsk, Neklinovsky, Novocherkassky, Millerovsky, Krasnosulinsky. Since January 1, 2021, the Volgodonsk Intermunicipal Ecological Waste Processing Complex has been launched and is operating for solid municipal waste management, it discusses the city of Volgodonsk and 9 nearby districts with a population of more than 400 thousand people; accepts up to 200 thousand tons of solid municipal waste waste per year, it includes: an automated waste sorting complex, a biocomposting site $[11,12]$, the actual solid municipal waste landfill.

The above-mentioned Volgodonsk Intermunicipal ecological waste processing complex is intended for processing more than $30 \%$ of organic waste into compost, and $15 \%$ of secondary raw materials obtained on its territory will be transferred to specialized waste 
processing enterprises. The remaining 7 Intermunicipal ecological waste processing complexes will start operating in 2022.

In connection with the above, the authors believe that the above-described large Intermunicipal Ecological Waste Processing Complexes for solid municipal waste management are likely to be also not free from the problem of ensuring environmental safety in connection with the development of surface man-made fires.

In particular, in 2018, according to the Administration of the Rostov Region, 21 manmade fires occurred at the solid municipal waste landfills in the Rostov Region, for 5 months of 2019 - 22 man-made fires. In 2020, which was characterized by aridity and high summer temperatures, a number of fairly large industrial fires were recorded at MSW landfills in the Rostov region.

The largest and most problematic cases of technogenic fires include: a fire at the solid waste landfill in Kamensk-Shakhtinsky on April 14, 2020, which covered an area of about $200 \mathrm{~m}^{2}$; fire on July 16, 2020 at the landfill in md. Leventsovka, located within the city of Rostov-on-Don on an area of $500 \mathrm{~m}^{2}$, as well as a fire on September 18-19, 2020 at the Volgodonsk solid waste landfill on an area of more than $2,500 \mathrm{~m}^{2}$.

It should be noted that the changes in the reform of economic management that have occurred in the Russian Federation over the past ten years have led, among other things, to unforeseen negative consequences in the organization of the safe use of solid municipal waste landfills, especially in the field of their protection from dangerous industrial fires developing in surface layer of waste $[13,14]$.

In this regard, we would like to emphasize that not only the number of man-made fires on the territories of solid municipal waste landfills (solid municipal waste) has increased with the amount of accepted household waste not decreasing, but the conditions for receiving MSW at landfills have also become more complicated due to changes in legislation in this area, the level of environmental literacy continues to decrease. the administrative staff of these enterprises and the population.

As a result of the above, it became necessary to revise the existing geoecological strategic concept for managing the activities of solid municipal waste landfills (solid municipal waste) and develop a new one, which will make it possible to develop adequate measures for managing environmental safety at solid municipal waste landfills [15].

Hence, the purpose of this study is to search for and develop modern technical devices to reduce the danger of the spread and development of man-made fires in the surface layer of household waste within the solid municipal waste landfills.

At the same time, it is necessary to monitor such hazardous technogenic objects to streamline the system of knowledge about them, which will allow timely and efficiently manage current problems, as well as predict the development of geoecologically hazardous situations, including the occurrence and development of technogenic fires at solid municipal waste landfills (solid municipal waste). It is especially important to organize a system of geoecological monitoring to improve the environmental safety of solid municipal waste landfills (solid municipal waste) within the territories located near settlements.

The need to improve the system of measures to improve the environmental safety of solid municipal waste landfills (solid municipal waste) and the relevance of research in these conditions confirm the cases of technogenic fires, which cause significant pollution of ground air with combustion products, including carcinogenic and toxic ones, and also cause social damage, including social losses.

\section{The Discussion Of The Results}


To implement the above research goal, the authors propose to use a modern device - an innovative mechanical fire-fighting hydraulic drill, designed to wet the burning deep layers of consumption waste with a fire-extinguishing liquid.

This device will make it possible to timely add a certain amount of extinguishing liquid to the surface layer of household waste, which, as it seems, will prevent the development and spread of technogenic fires on the territories of solid municipal waste landfills, causing high social and environmental damage.

A lot of devices for extinguishing industrial fires are known, containing a perforated tube with a tip and hollow handles, one of which is equipped with a fitting for connecting a flexible hose communicated with a source of extinguishing liquid, a control valve for the supply of extinguishing liquid.

However, the disadvantages of this kind of devices are also well known, which are:

- the possibility of supplying extinguishing liquid under pressure only to the sides of the perforated tube of the barrel for extinguishing;

- fire-extinguishing liquid enters the deep layers of burning peat constantly and by gravity.

Several studies have also described a fire-fighting barrel containing a perforated tube with a tip.

In this regard, the use of the innovative device proposed in this work will increase the efficiency of extinguishing technogenic fires through the use of process mechanization systems and the use of new materials.

The technical result obtained during the implementation of this structural solution will, as it seems to the authors, increase the efficiency of extinguishing a technogenic fire with a device by supplying extinguishing liquid only to the zones of high-temperature combustion of a layer of household waste and increasing the convenience of using the claimed semiautomatic device.

The specified problem - increasing the efficiency of extinguishing technogenic fires at solid municipal waste landfills and preventing these geoecologically dangerous situations is solved through a number of technical improvements. So, the proposed device for extinguishing technogenic fires at solid waste landfills contains:

- a distributor of extinguishing liquid in the form of a hollow body, which is equipped with an inlet pipe for communication with a source of extinguishing liquid and outlet pipes;

- the outlet is connected by means of a removable flexible hose with an extinguishing barrel, which is equipped with a valve that regulates the supply of extinguishing liquid to it.

In this case, the barrel is made in the form of a perforated tube, the perforations of which are made in the form of holes closed by a lid equipped with an alloy element with the ability to "memory" the shape.

The barrel, made in the form of a tube, is equipped with an Archimedean screw and a carbide tip.

The holes covered with a shape memory alloy cover are located between the turns of the Archimedean screw. The covers have the ability to open in burning peat in the direction of rotation of the barrel, equipped with an Archimedean screw.

The extinguishing liquid distributor can be made with two coaxial through holes, into which the barrel is inserted. The extinguishing liquid from the stationary distributor enters the barrel through a series of holes in the barrel section located inside the extinguishing liquid distributor housing.

Free rotation of the hollow barrel in the fire-extinguishing liquid distributor housing is ensured by bearing and sealing assemblies.

Actually, the rotation of the barrel in a stationary, relative to the mobile unit, the body of the fire-extinguishing liquid distributor is provided by a hydraulic motor. 
The hydraulic motor, in turn, is driven by a standard oil pump such as an axial piston pump. Rotation, stopping and reverse of the hydraulic motor is provided by a three-position electrovalve, the fittings and controls of which are brought to the fire operator's control panel.

Making the barrel rotating, with an Archimedean screw, significantly reduces (in comparison with the prototype) the immersion time in burning peat soil, and a carbide drilltip will reduce the likelihood of the rotating barrel hitting a solid foundation of the soil when the barrel tube is buried into the ground.

This reduces the likelihood of device breakdown and, consequently, the likelihood of failure of the entire barrel, which in a technogenic fire in a layer of solid domestic waste, where there is nothing to replace the defective barrel, can adversely affect the extinguishing efficiency.

The execution of barrel perforations with additional covers that open only at high temperatures allows one to obtain a sequential opening of the barrel openings and, due to this, significantly increase the volume of supply of extinguishing liquid precisely to the hightemperature focus of combustion of the waste layer, that is, to increase the efficiency of extinguishing the fire site as a whole with economical the consumption of extinguishing liquid limited in the conditions of a technogenic fire.

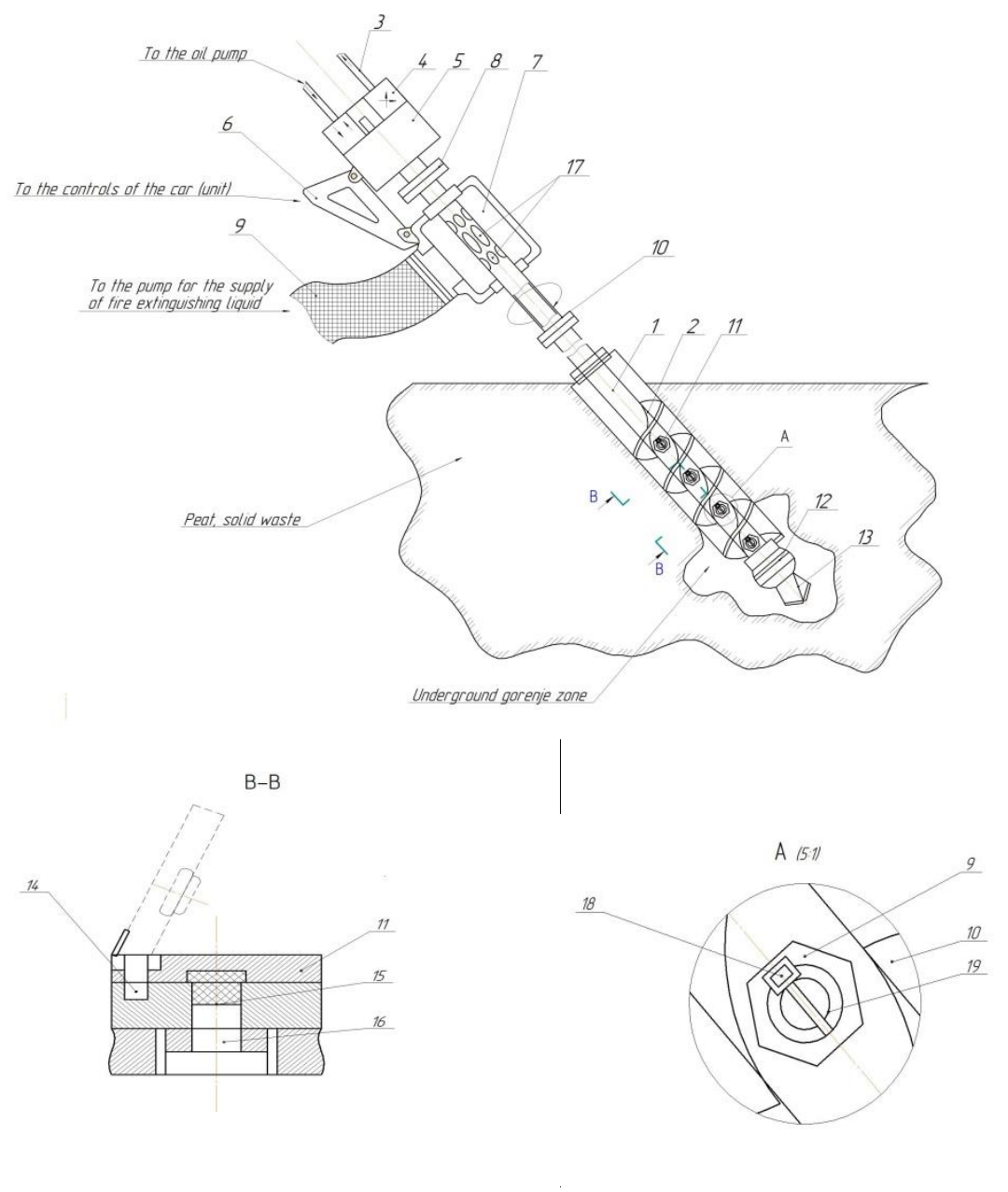

Fig. 1. Structural layout of a device for extinguishing a peat fire with a rotating barrel equipped with an Archimedean screw 
Figure 1 shows a device for extinguishing a peat fire with a rotating barrel equipped with an Archimedean screw contains a number of main units and parts:

1 - high pressure oil lines; 2 - three-position electro-pneumatic valve; 3 - hydraulic motor; 4 - power traverse of the mobile unit; 5- clutch connecting the hydraulic motor and the distributor shaft; 6 - removable flexible sleeve; 7 - distributor of extinguishing liquid in the form of a hollow body with coaxial bearing assemblies; 8 - coupling connecting the hollow shaft shafts; 9 - hydraulic drill; 10 - Archimedes screw; 11 - Initially closed lids provided with a shape memory alloy member; 12 - sleeve connecting the barrel and drill-tip; 13 - carbide drill tip; 14 - cover fastening; 15 - initially closed lid; 16 - rubber seal; 17 nozzle for extinguishing liquid; 18 - holes in the distributor shaft; 19 - element with shape memory effect; 20 - cover-element assembly with shape memory effect-nozzle, assembled.

The execution of the fire extinguishing liquid distributor with two outlet nozzles, with reduced dimensions and a handle, makes it easier to transfer the unit to the fire site of all the components of the device for extinguishing man-made fires, namely the barrel for extinguishing, removable flexible hoses and the fire extinguishing liquid distributor.

This improves the convenience in using the device and has a positive effect on increasing the extinguishing efficiency.

The technical solution proposed in this study is illustrated in Figure 1.

So, figure 1 of figure 1 shows a general view of a device for extinguishing peat fires with a rotating barrel, equipped with an Archimedean screw connected directly to the distributor of extinguishing liquid.

Further, figure 2 of figure 1 shows a barrel bore closed with a plug with elements based on a shape memory alloy (top view).

Finally, Figure 3 of Figure 1 shows a barrel bore closed with a shape memory alloy plug (side view).

The authors of this study believe that the device should function as follows.

A specialist involved in extinguishing a man-made fire brings the traverse 4 of the mobile unit, with a device for extinguishing a man-made fire with a rotating barrel attached to it, to the fire site. A removable flexible hose 6 is connected to the fire-extinguishing liquid distributor 7 in the form of a hollow body with coaxial bearing assemblies. Considering the large dimensions of the device, its weight is borne by the hydraulic manipulator.

The extinguishing liquid dispenser is oriented approximately over the expected underground or buried fire.

So, the hydraulic motor 3 is driven by the energy of the working fluid (hydraulic oil) supplied to it through the high pressure oil line 1 and the three-position electro-pneumatic valve 2 .

The parameters of the barrel rotation (for deepening, stopping, to the surface) are selected by the operator using the armature controlling the three-position electro-pneumatic valve 2 , thereby increasing the convenience in using the claimed device. The barrel (hydrodrill 9) equipped with an Archimedean screw 10 deepens into the burning loose peat soil.

Upon reaching the expected underground subsurface fire source, the rotation of the shaft can be stopped.

The extinguishing liquid (water with a wetting agent) is supplied under pressure from the tank of the mobile unit through a removable flexible hose 6 into the fire extinguishing liquid distributor 7 in the form of a hollow body with coaxial bearing assemblies, then through holes 18 into the coupling 12 of the hollow shaft shafts, and then into the hydraulic drill 9 The initially closed lids 15 , heated to the temperature of the onset of the phase transition in the shape memory alloy, open. Through the holes of the nozzles 17, the extinguishing liquid enters directly into the seat of a subsurface man-made fire in the waste layer. 
After the end of extinguishing, the barrel is rotated in the opposite direction, removed to the surface, the soil is dropped from the Archimedean screw at high speeds, the nozzle covers are closed and the mobile unit or traverse is relocated using a hydraulic manipulator to another prospective fire source.

In a loose layer of consumption waste, it is allowed to move the rotating shaft without lifting to the surface horizontally in any direction, at a distance permissible by the technical characteristics of the hydraulic manipulator of the mobile unit.

It is possible to experimentally confirm the effectiveness of shafts buried in a burning loose layer of consumption waste using the developed installation, the diagram of which is shown in Figure 2.

As shown in Figure 2, the experimental setup for studying the combustion parameters of buried waste layers and the efficiency of extinguishing with a hydrodrill includes:

1 - non-combustible base,

2 - fire-brick box,

3 - fire hose model,

4 - hydraulic valve model,

5 - hydraulic drill model with perforation,

6 - peat soil layer,

7 - burning loose peat soil,

8 - hollow copper tube,

9 - tripod,

10 - thermocouple,

11 - multimeter with temperature measurement function,

12 - water pump,

13 - tank,

14 - water with wetting agent.

A description of the operation of the experimental setup for studying the combustion parameters of buried waste layers and the efficiency of extinguishing with a hydraulic drill is not required, since it practically coincides with the operation of the devices described above, with the exception of the function of rotation of the hydraulic drill barrel.

With the help of self-opening nozzles, the burning subsurface layers of consumption waste are successively wetted, thereby achieving an optimal zone for the supply of extinguishing liquid.

The effectiveness of extinguishing subsurface fires can be increased by the addition of special chemical compounds to the water, which increase the efficiency of water use by $2 \ldots$ 4 times.

Sulfanol is the best known wetting chemical. It is a light yellow powder that dissolves quickly in water. Its addition in the amount of $30 \mathrm{~g}$ per bucket of water $(0.3 \%$ by weight to water or other solutions) increases the wetting properties. 


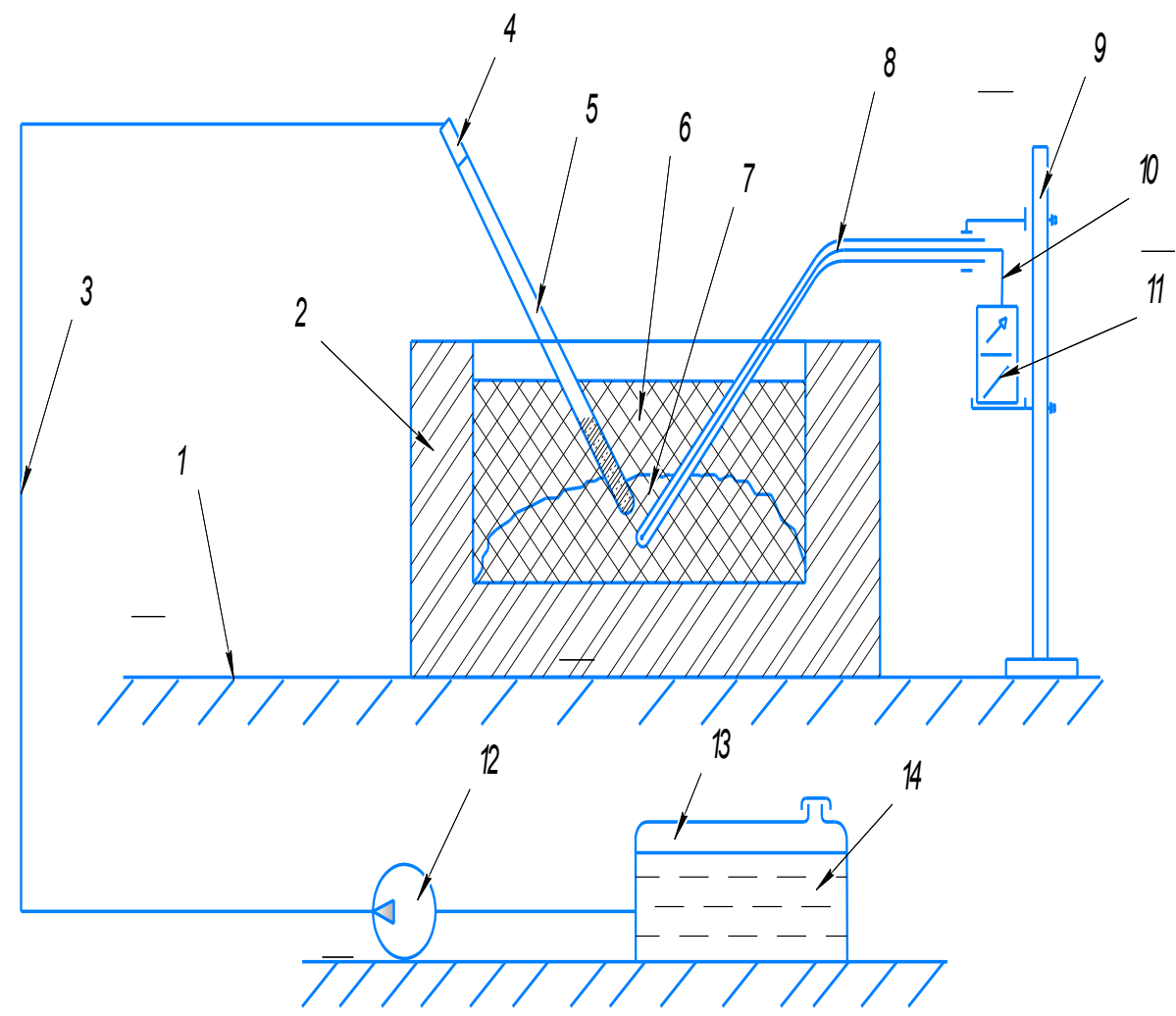

Fig. 2. Schematic diagram of an experimental setup for studying the combustion parameters of buried peat layers and the efficiency of extinguishing with a hydraulic drill

As surfactants (surfactants), it is also possible to recommend agents based on sulfanol and other wetting agents, which are used to fight persistent fires in the waste layer, they are able to quickly penetrate into thick layers of household waste, providing a decrease in the intensity of combustion and contributing to the elimination of a fire in the result.

However, the low degree of biodegradability of these surfactants will contribute to environmental pollution.

In this regard, as it seems to the authors of the study, the most promising wetting agents in this regard can be wetting agents developed on the basis of natural components, these include, for example, saponins, pectins isolated from fruits and fruits; cellulose derivatives, lecithin, glucosides and the like.

\section{Conclusions}

Based on the results obtained, it can be seen that the problem of fires at solid municipal waste landfills (solid municipal waste) is very urgent, while the frequency of man-made fires at these landfills has been steadily increasing in recent years. The situation is complicated by the proximity of settlements, which, taking into account geographical factors, ensures the diffusion of substances polluting the surface layer of the atmosphere, increasing social and environmental risks. One of the modern options for solving the problem considered in the article is the innovative mechanical fire-fighting hydraulic drill proposed by the authors of the work, designed to wet the burning deep layers of consumption waste with a fireextinguishing liquid, the socio-ecological efficiency of which can be increased by adding 
natural biodegradable components to the composition of the mentioned liquid. This direction of scientific research, as the authors of the study believe, is very promising and has a high scientific and practical value.

\section{References}

1. S.S. Andreev, E.S. Popova, Ecologic-geographical estimation of climatic comfortness of Rostov-on-Don, European Journal of Natural History, European Journal of Natural History 5, 32-34 (2013)

2. E.S. Andreeva, P.V. Klimov, I.N. Lipovitskaya, S.S. Andreev, O.V. Denisov, Approaches to the assessment of non-carcinogenic risk to public health on the city of Rostov-on-Don, International Multidisciplinary Scientific GeoConference SGEM 195.2, 115-122 (2019) doi: 10.5593/sgem2019/5.2/S20.015

3. S.S. Andreev, E.S. Popova, Assessment of the climatic comfort of the coastal area on the example of the city of Tuapse, Bulletin of St. Petersburg University 7- 4, 145-150 (2015)

4. K. M. Sangamithirai, J. Jayapriya, J. Hema, Ravi Manoj, Evaluation of in-vessel cocomposting of yard waste and development of kinetic models for co-composting, Int $\mathbf{J}$ Recycl Org Waste Agricult 4, 157-165 (2015) doi: 10.1007/s40093-015-0095-1

5. V.M. Smolyaninov, T.V. Ovchinnikova, T.V. Ashikhmina, P.S. Kuprienko Forecasting changes in hydrologal and hydrogeological conditions in the water intake area through the example of water supply in Voronezh, Water and ecology: problems and solutions 2(78), 50-58 (2019) doi: 10.23968/2305-3488.2019.24.2.50-58

6. T.V. Ashikhmina, T. Ovchinnikova and P.S. Kupriyenko, Issues of solid waste influence on the environment, 204 (Saarbrucken: LMBERT Academic Publishing, 2014)

7. I. Pasiecznik, K.P. Banaszkiewicz, J. Leoniewska-Gogola, Selective waste collection in the detached housing area, Journal of Ecological Engineering 16(3), 124-129 (2015)

8. P. Mandal, M. K. Chaturvedi, J. K. Bassin, A. N. Vaidya, R. K. Gupta, Qualitative assessment of municipal solid waste compost by indexing method, Int J Recycl Org Waste Agricult 3, 133-139 (2014)

9. G.N. Chattopadhyay, Use of vermicomposting biotechnology for recycling organic wastes in agriculture, International Journal of Recycling of Organic Waste in Agriculture 1(8), 6 (2012)

10. S.U. Salmon, M.R. Hipsey, G.W. Wake, G.N. Ivey and C.E. Oldham, Quantifying lake water quality evolution: coupled geochemistry, hydrodynamics, and aquatic ecology in an acidic pit lake, Environmental Science and Technology 51 - 17, 9864-9875 (2017) doi: 10.1021/acs.est.7b01432

11. L. B Vampilova, A. A Sokolova, N. A Brodskaya, D. V Sevastyanov, and A. N Trifonov, Problems of geoturism development in the north-western recreational region of Russia, International Multidisciplinary Scientific GeoConference "Surveying Geology and Mining Ecology Management" SGEM 19-5.2, 731-738 (2018) doi: 10.5593/sgem2018/5.2/S20.095

12. Van Etten, E. J. B., McCullough, C. D. and Lund, M. A., Setting goals and choosing appropriate reference sites for restoring mine pit lakes as aquatic ecosystems: case study from South West Australia, Mining Technology, Transactions of the Institutions of Mining and Metallurgy, Section A 123-1, 9-19 (2014) doi: 10.1179/1743286313Y.0000000051 
13. M. L. Blanchette, and M. A Lund, Pit lakes are a global legacy of mining: an integrated approach to achieving sustainable ecosystems and value for communities, Current Opinion in Environmental Sustainability 23, 28-34 (2016) doi: 10.1016/j.cosust.2016.11.012

14. Ya. A Dmitrakova, and E. V Abakumov, Restoration of soils and vegetation on reclamation sites of the Kingisepp phosphorite field. Eurasian Soil Science 51-5, 588597 (2018) doi: 10.1134/S1064229318050022

15. V. V Kevbrin, Isolation and cultivation of alkaliphiles, Advances in Biochemical Engineering/ Biotechnology, Berlin, Heidelberg: Springer, 1-32 (2019) doi: 10.1007/10_2018_84 